\title{
MECHANICAL SURFACE TREATMENTS TO OPTIMIZE THE FATIGUE BEHAVIOUR OF QUENCHED AND TEMPERED HIGH STRENGTH STEELS
}

\author{
E. Segurado, F.J. Belzunce and I. Fernández Pariente \\ University of Oviedo (Engineering Polytechnic School), Materials Science Department, \\ 33203 Gijón, Spain
}

\begin{abstract}
The aim of this work is to maximize the fatigue life of an AISI 4340 steel (quenched and tempered at $200^{\circ} \mathrm{C}$ ) with a tensile strength of $2000 \mathrm{MPa}$. To do so, different shot peening treatments were studied. Some of these treatments used traditional steel shots made of cut wire, and others used ceramic shots made of zirconia (Zirshot Y 300), which had not been used in previous works and had to be completely characterized. Additionally, secondary peening treatments and grit blasting were applied with the objective of decreasing the surface damage induced by the previous treatment.
\end{abstract}

To characterize both primary and secondary shot peening treatments, the surface topography of the samples was analysed using a roughness tester and scanning electron microscopy. (SEM). The compressive residual stress field induced by these treatments was measured with X-ray diffraction (XRD). Afterwards, fatigue behaviour was studied by means of 4-point rotating bending tests. Fracture surfaces were analysed using SEM.

The results showed that an optimum combination of surface treatments (primary + secondary) avoided the initiation of cracks in the surface of the specimens (typical characteristic of fatigue failure under bending loads). In these cases, crack initiation always took place beneath the compressive stress field induced by the treatments, in alumina inclusions that acted as stress concentrators. Furthermore, the size and distribution of these alumina inclusions (analysed using SEM) allowed determining the steel threshold amplitude of the stress intensity factor, $\Delta \mathrm{K}_{\mathrm{th}}$.

KEYWORDS: Fatigue, shot peening, residual stresses, structural steels, stress intensity factor threshold. 


\section{INTRODUCTION}

Shot peening is a widely used cold surface treatment to improve the fatigue strength of industrial metallic components both quickly and economically. It consists in projecting hard, tiny, spherical beads onto the component surface to induce surface plastic deformation, which constrains the layer just below the surface. This treatment induces some beneficial effects in the material such as compressive residual stress and surface hardening, and others not so beneficial effects such as an increase in roughness and a certain degree of surface damage. When properly controlled, however, it can provide significant enhancements, especially to ameliorate the fatigue behaviour of components subjected to dynamic loads $[1,2,3]$.

Almen intensity is a parameter that gives an idea of the amount of energy that is induced in a material during treatment and depends on the size, hardness and velocity of the projectiles. The optimal peening intensity to obtain the best fatigue behaviour depends on the hardness or mechanical strength of the treated steel. For example, Tekeli [4] applied peening intensities of between $10 \mathrm{~A}$ and 30A to a quenched and tempered SAE 9245 steel, obtaining the highest fatigue strength when using 20-25A peening treatments, while also observing a clear decrease in fatigue strength when the peening intensity was further increased. On the other hand, Aggarwald et al. [5] obtained the best fatigue performance with an Almen intensity of 17A on a tempered martensitic steel with a tensile strength of $1256 \mathrm{MPa}$ and an optimum shot peening treatment of only 6A was obtained by Torres and Voorwald [6] on a quenched and tempered 4340 steel grade with a tensile strength of $1864 \mathrm{MPa}$. Moreover, the effect of shot peening parameters (shot size, air pressure and peening time) on the Almen intensity, surface roughness and surface hardness of an AISI 1070 steel was systematically studied in [7]. As a summary of previous works, it can be said that low intensity treatments give rise to shallow depths submitted to high compressive stresses, while high intensity treatments produce high roughness and surface damage where cracks can easily initiate under cyclic loads. It has also been shown that, under optimal shot peening treatments, fatigue cracks initiate below the layer affected by the compressive residual stresses induced by shot peening treatment. Hence, under these optimized treatments, the compressive layer is able to fully protect the surface region and crack initiation is displaced to deeper sites related to the presence of microstructural heterogeneities or stress concentrators. 
In a previous study performed on the same steel grade used in this research (a quenched $200^{\circ} \mathrm{C}$ tempered AISI 4340 steel with a tensile strength of $2000 \mathrm{MPa}$ ), the best fatigue behaviour conferred by single shot peening treatment (SP) was found to correspond to an Almen intensity of 14A [8]. Treatments at a higher Almen intensity, such as SP19A, induce deeper residual stress profiles, but the steel's fatigue behaviour was not enhanced. This is because the excess energy deteriorates the surface of the material, generating small notches, which accelerate the initiation of cracks under fatigue loads [9].

On the other hand, different authors have demonstrated the possibility of increasing the fatigue life of components using double surface treatments [9-11]. Basically, double treatments consist in applying a high intensity peening treatment, which induces a deep region of high compressive stresses, followed by a second surface treatment to reduce the roughness induced by the initial treatment and mitigate surface damage. Polishing, vibratory finishing, grit blasting and a second shot peening treatment using smaller beads and lower intensities have been found to be effective second treatments.

The aim of this paper is to study the effect of second surface modification treatments on the fatigue behaviour of samples previously submitted to a high Almen intensity shot peening treatment (19A). Simple low intensity shot peening treatments (8A) with zirconia shot were also performed. Zirconia shots have a much more spherical, perfect, homogeneous morphology and, although they induce a shallower residual stress profile, they generate less surface damage than high intensity shot peening.

\section{EXPERIMENTAL PROCEDURE}

\subsection{Material}

The study was performed on a 41NiCrMo7-3-2 (AISI 4340) steel, which is widely employed in the automotive and aircraft industries and in the manufacture of machine components due to its advantageous combination of strength and toughness. It was supplied in bars with a nominal diameter of $16 \mathrm{~mm}$. The bars were austenitized at $850^{\circ} \mathrm{C}$ for 45 minutes, quenched in water, tempered at $200^{\circ} \mathrm{C}$ for 150 minutes and finally cooled in air. The chemical composition of the steel is shown in Table 1. 
Table 1. Chemical composition of AISI 4340 steel ( $\%$ by weight).

\begin{tabular}{|c|c|c|c|c|c|c|}
\hline $\mathrm{C}$ & $\mathrm{Mn}$ & $\mathrm{Si}$ & $\mathrm{Ni}$ & $\mathrm{Cr}$ & $\mathrm{Mo}$ & $\mathrm{Cu}$ \\
\hline 0.41 & 0.71 & 0.26 & 1.92 & 0.87 & 0.23 & 0.21 \\
\hline
\end{tabular}

Table 2 shows the values of the elastic modulus $(E)$, yield strength $\left(\sigma_{y}\right)$, tensile strength $\left(\sigma_{\mathrm{F}}\right)$, tensile elongation at failure $\left(\varepsilon_{\mathrm{F}}\right)$, reduction of area $(\mathrm{Z})$ and the $\mathrm{k}$ and $\mathrm{n}$ constants of the Hollomon hardening plastic law $\left(\sigma=\mathrm{k} \varepsilon^{\mathrm{n}}\right)$ of the heat-treated steel [8].

Table 2. Tensile properties of $\mathrm{Q}+\mathrm{T} 200^{\circ} \mathrm{C}$ AISI 4340 steel

\begin{tabular}{|c|c|c|c|c|c|c|}
\hline $\mathrm{E}(\mathrm{GPa})$ & $\sigma_{\mathrm{y}}(\mathrm{MPa})$ & $\sigma_{\mathrm{F}}(\mathrm{MPa})$ & $\varepsilon_{\mathrm{F}}(\%)$ & $\mathrm{Z}(\%)$ & $\mathrm{n}$ & $\mathrm{k}(\mathrm{MPa})$ \\
\hline 200 & 1596 & 2000 & 11 & 50 & 0.24 & 5029 \\
\hline
\end{tabular}

After applying the afore-mentioned heat treatment to several steel bars of approximately $300 \mathrm{~mm}$ in length, two different types of specimens were obtained: flat disks with a thickness of $10 \mathrm{~mm}$ cut transversally from the bars, and fatigue specimens. The surface treatments described below were performed on both kinds of specimens.

\subsection{Surface treatments}

\subsubsection{Shot peening treatment}

Shot peening treatments were applied using a GUYSON Euroblast 4 PF direct compressed air system, consisting of a G27 type tank, a 75/16 type motorized cyclone and a DC400 dust collector. The diameter of the peening nozzle was $5 \mathrm{~mm}$ and the distance between the nozzle and the work piece was $230 \mathrm{~mm}$. A $90^{\circ}$ impact angle was employed in all cases.

Several series of samples were submitted to high intensity shot peening treatment (19A) using cut wire shots with rounded-off edges $(670-730 \mathrm{HV})$ with an average diameter of $0.7 \mathrm{~mm}$ (CW0.7) and 100\% coverage. Following this treatment, all the specimens were submitted to a second treatment in order to reduce surface damage. 
Other samples were submitted to low intensity shot peening treatments (8A) using zirconia ceramic shots (ZIRSHOT Y300) with an average diameter of $0.3 \mathrm{~mm}$ (ZS0.3) using a coverage level of $100 \%$.

The shot peening intensities applied in this study were produced according to SAE J442 [12] and J443 [13] specifications by means of Almen strips type A.

Figure 1 are micrographics that shows the morphology of both the $0.3 \mathrm{~mm}$ zirconia ceramic shots and steel cut wire shots. The perfect spherical morphology of the ceramic shots is worth noting.

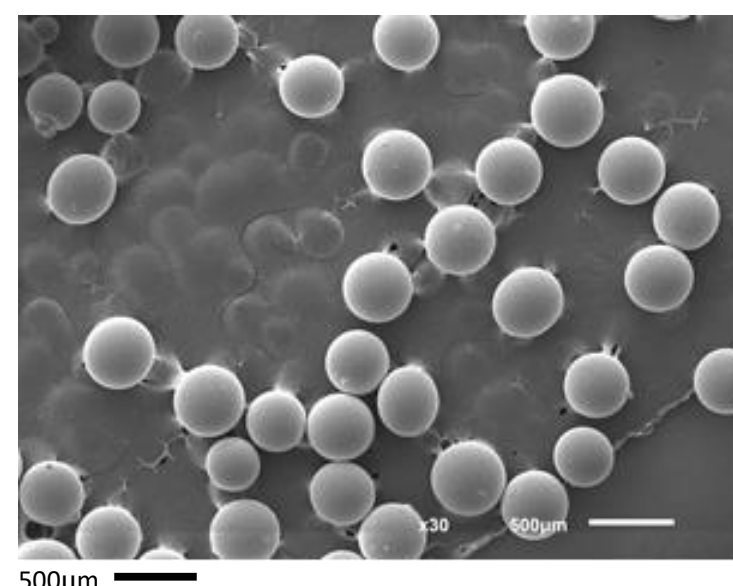

a)

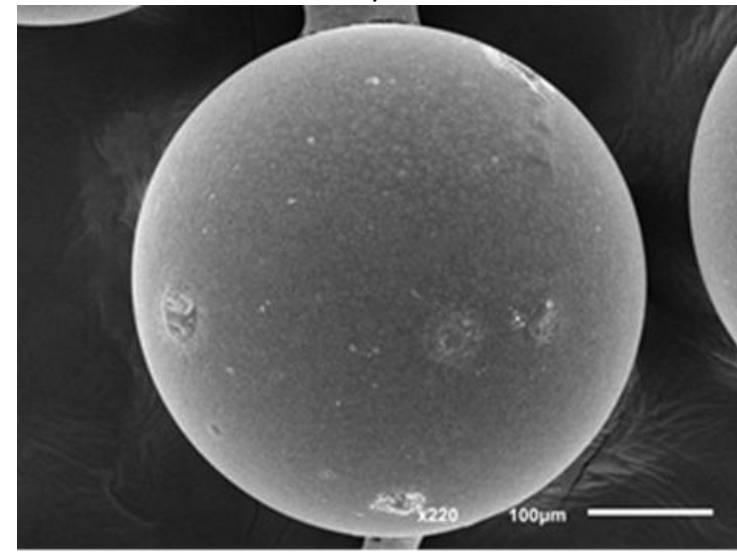

$100 \mu \mathrm{m}$

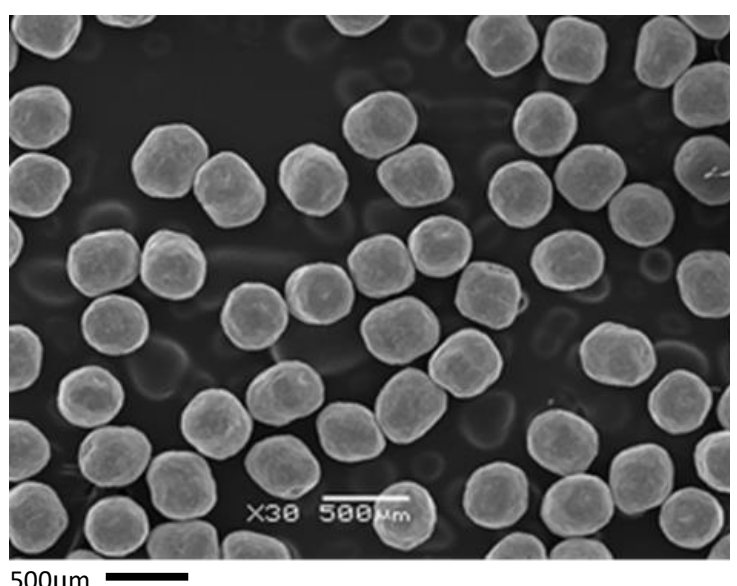

b)

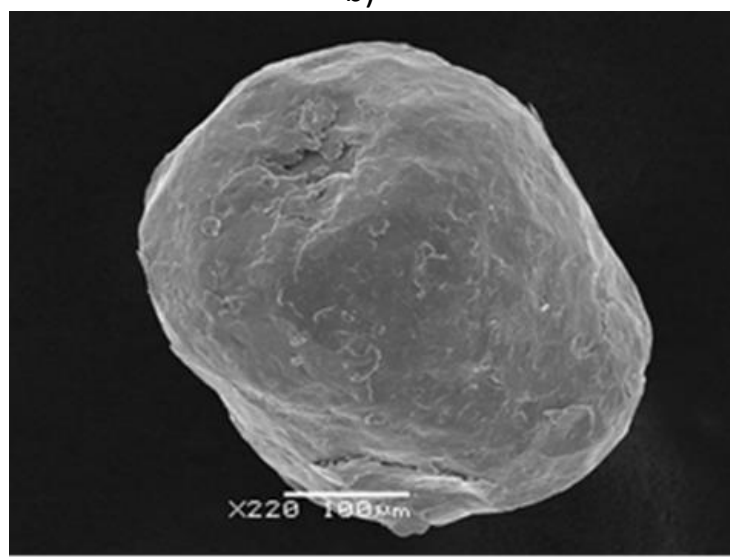

$100 \mu \mathrm{m}$

c)

d)

Figure 1. Shot peening shots

a) zirconia $30 x, b)$ cut wire steel $30 x$, c) zirconia $220 x$, d) cut wire steel $220 x$. 


\subsubsection{Second treatments}

Second peening treatments using a low Almen intensity, 8A, was used as a secondary treatment under two different coverages (100\% and 200\%). Two different projectiles were employed: steel cut wire shots with a diameter of $0.3 \mathrm{~mm}$ (CW0.3), and zirconia ceramic beads (ZIRSHOT Y300), also with an average diameter of $0.3 \mathrm{~mm}$ (ZS0.3).

Grit blasting is a surface treatment usually used for eliminating surface oxide layers in an effective way and we have used this treatment in this work in order to remove the surface layer in which different defects had been produced in the prior SP19A treatment. A second surface treatment consisting in grit blasting fine alumina powder (White Corundum Cristalba CAR 0/0.1) was also then applied using the same direct compressed air machine. The alumina powder was almost pure alumina with a Knoop hardness of $2100 \mathrm{~kg} / \mathrm{mm}^{2}$ and a grit size below $0.1 \mathrm{~mm}$.

Figure 2 shows two micrographics of the alumina powder taken under the scanning electron microscope: these alumina particles have angular shapes, so the main effect of grit blasting is the progressive and controlled removal of surface material layers.

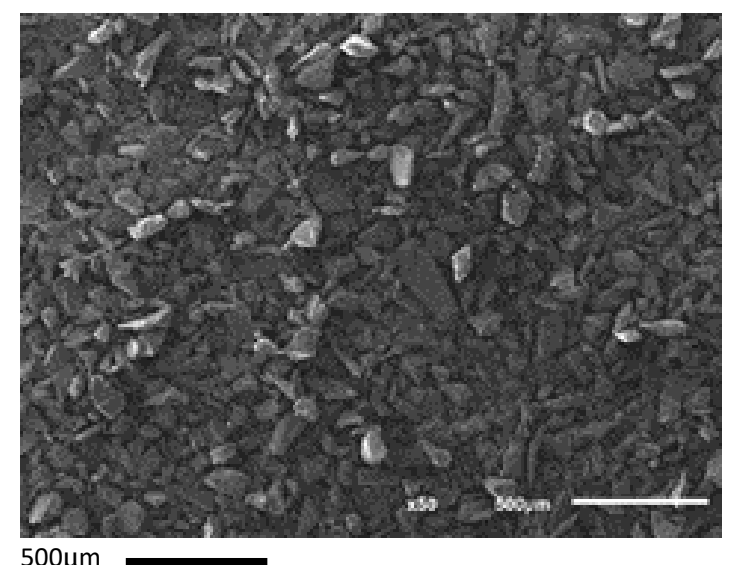

a)

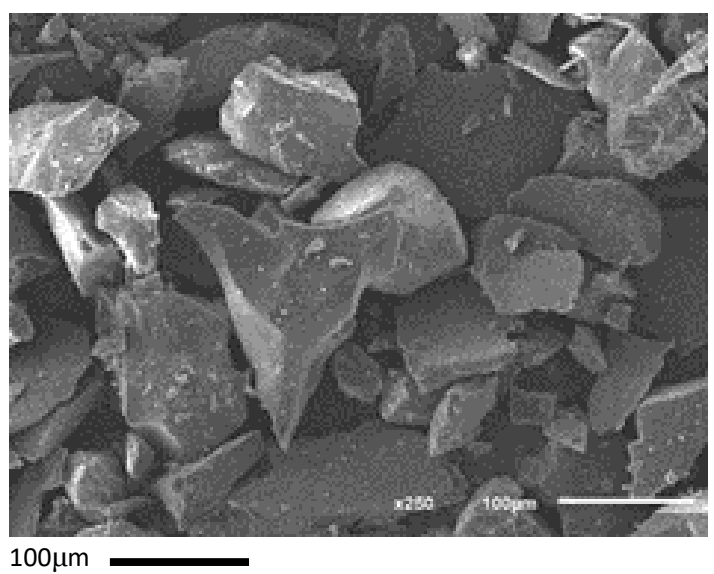

b)

Figure 2. Alumina grit powders CAR0/0.1: a) 50x, b) 250x

Alumina grit blasting (GB) was applied under an air pressure of 2 bar for two different treatment times, $60 \mathrm{~s}$ and $90 \mathrm{~s}$.

Table 3 specifies the nomenclature used for treatment identification. 
Table 3. Nomenclature used for each surface treatments

\begin{tabular}{|c|c|c|c|c|}
\hline Treatment & $\begin{array}{c}\text { Almen } \\
\text { intensity }\end{array}$ & Shots & $\begin{array}{c}\text { Coverage/ } \\
\text { time }\end{array}$ & Nomenclature \\
\hline Grit blasting & & Alumina & $60 \mathrm{~s}$ & $60 \mathrm{sGB}$ \\
\hline Grit blasting & & Alumina & $90 \mathrm{~s}$ & $90 \mathrm{sGB}$ \\
\hline Shot peening & $19 \mathrm{~A}$ & Cut Wire 0,7 & $100 \%$ & SP19A \\
\hline Shot peening & $8 \mathrm{~A}$ & Cut Wire 0,3 & $100 \%$ & SP8A-CW $(100 \%)$ \\
\hline Shot peening & $8 \mathrm{~A}$ & Cut Wire 0,3 & $200 \%$ & SP8A-CW $(200 \%)$ \\
\hline Shot peening & $8 \mathrm{~A}$ & ZirShot 0,3 & $100 \%$ & SP8A-ZS $(100 \%)$ \\
\hline Shot peening & $8 \mathrm{~A}$ & ZirShot 0,3 & $200 \%$ & SP8A-ZS $(200 \%)$ \\
\hline
\end{tabular}

\subsection{Characterization techniques}

\subsubsection{Roughness measurements}

Roughness was measured in all specimens after both the first shot peening and the second treatment. Five different roughness profiles were obtained for each sample and an average of the main parameters $\left(\mathrm{R}_{\mathrm{a}}\right.$ and $\left.\mathrm{R}_{\max }\right)$ was reported as per the ISO1302 DIN 4768 standard. Surface roughness measurements were performed with a Mahr Marsurf M300 roughness tester by means of the average roughness $\mathrm{Ra}$ and the Rmax parameter, which is the maximum of the five $R_{\text {imax }}$ within the assessment length of $4.8 \mathrm{~mm}$, where $R_{\text {imax }}$ is the maximum peak-to valley height of the profile in each of the five aforementioned measurements. These values are known to be the most representative parameters of the roughness profile, as they are directly related to the provided stress concentration factor.

\subsubsection{Residual stress profile}

In-depth residual stress profiles were determined by X-ray diffraction using the $\sin ^{2} \Psi$ method $[14,15]$. With the aim of removing material without modifying the residual stress field, electro-polishing was carried out using 94\% acetic acid and 6\% perchloric acid as the electrolyte under a voltage of $40-50 \mathrm{~V}$. The slight stress relaxation produced by electro-polishing was also taken into account and corrected in accordance with Sikarskie 
[16], who has developed a method based on the Moore and Evans procedure [17]. Residual stress measurements were performed using a Stresstech X-Stress 3000 G3R diffractometer, the $\mathrm{K}_{\alpha}$ chromium wavelength $(\lambda=0.2291 \mathrm{~nm})$, (211) diffraction planes, with a diffraction angle of around $156^{\circ}$, and an elastic constant $\mathrm{E} /(1+v)=168.9 \mathrm{GPa}$ [18].

Diffraction data were determined in three directions of the sample plane, $-45,0$ and $+45^{\circ}$, an average of these results being reported in all cases.

The procedure began with a surface measurement, followed by the removal of a layer of material around $20 \mu \mathrm{m}$ thick, and then a new measurement was performed. This process was repeated as many times as necessary until tensile residual stress was obtained. The residual stress was always measured at the same location, at the centre of the specimen, which had previously been marked with a permanent marker.

\subsubsection{Rotating fatigue tests}

Fatigue tests were carried out on a four-point bend loading R.R. Moore rotating beam fatigue test machine (fully-reversed loading, $\mathrm{R}=-1$ ). Tests were performed at room temperature and $5700 \mathrm{rpm}(95 \mathrm{~Hz})$, using cylindrical specimens with a calibrated length of $12.8 \mathrm{~mm}$ and $6 \mathrm{~mm}$ in diameter.

The maximum alternative surface stress applied in the fatigue tests was always $1100 \mathrm{MPa}$, which corresponds to $55 \%$ of the ultimate tensile strength of the steel, $\sigma_{\mathrm{F}}$. This load was chosen after performing different tests varying this parameter, so that it was located just above the fatigue limit of the steel and, in the case of the best treatments, not too far from it. The number of specimens tested under each condition varied between 4 and 9 and the fatigue results were expressed as average results, although individual values were also reported.

Once the specimens had failed, their failure surfaces were observed under SEM microscopy provided by an electron probe energy dispersive microanalysis to detect the location of the origin of the fatigue crack and measure other significant microstructural parameters in the fracture surface.

\section{RESULTS}




\subsection{Roughness and surface topography}

Table 4 shows the average values of the roughness parameters, $R_{a}$ and $R_{\max }$, measured on the fatigue samples after the different surface treatments.

Table 4. Roughness parameters measured after the applied surface treatments

\begin{tabular}{|l|l|l|}
\hline \multicolumn{1}{|c|}{ Treatments } & $\mathrm{R}_{\mathrm{a}}(\mu \mathrm{m})$ & $\mathrm{R}_{\max }(\mu \mathrm{m})$ \\
\hline SP19A & $2.1 \pm 0.17$ & $15.6 \pm 2.2$ \\
\hline SP19A+60sGB & $1.5 \pm 0.1$ & $12.2 \pm 1.5$ \\
\hline SP19A+90sGB & $1.5 \pm 0.1$ & $12.0 \pm 1.3$ \\
\hline SP19A+SP8A-CW(100\%) & $1.8 \pm 0.1$ & $13.0 \pm 1.4$ \\
\hline SP19A+SP8A-CW(200\%) & $2.1 \pm 0.2$ & $14.6 \pm 1.8$ \\
\hline SP19A+SP8A-ZS(100\%) & $2.0 \pm 0.2$ & $14.6 \pm 1.3$ \\
\hline SP19A+SP8A-ZS(200\%) & $2.0 \pm 0.1$ & $14.8 \pm 0.6$ \\
\hline SP8A-ZS(100\%) & $1.4 \pm 0.1$ & $11.0 \pm 2.7$ \\
\hline
\end{tabular}
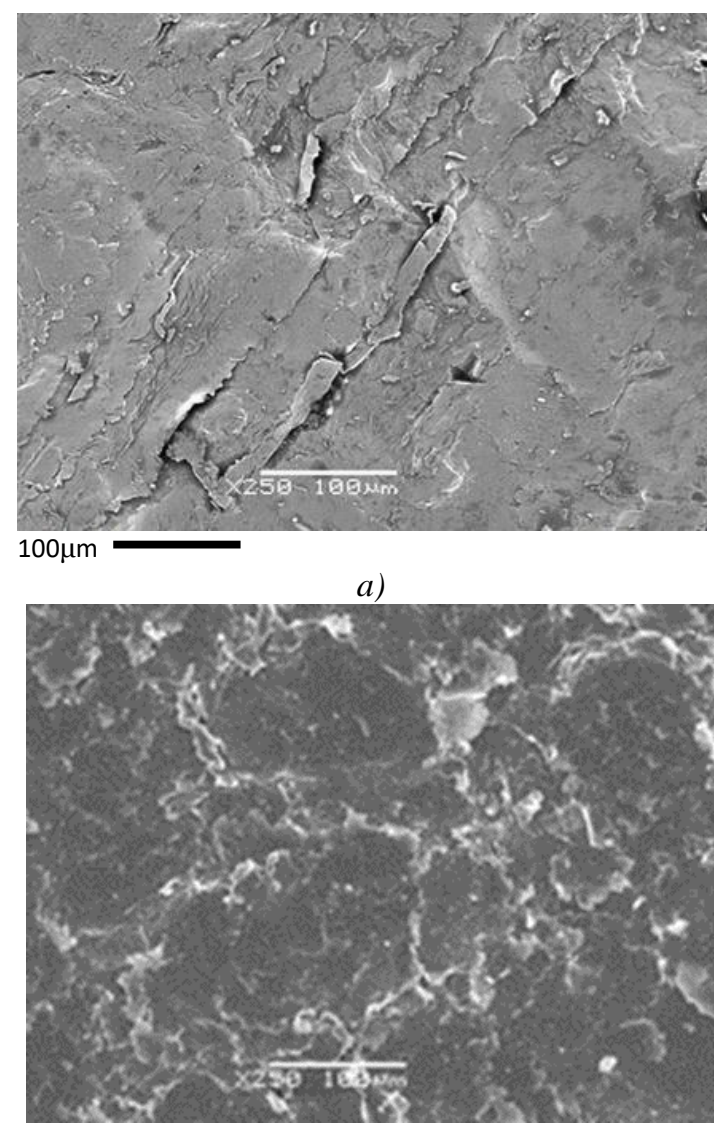

$100 \mu \mathrm{m}$

c)

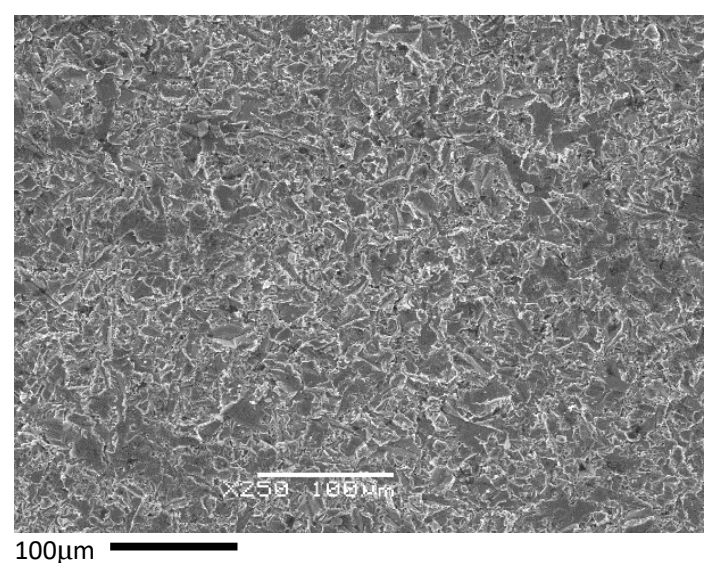

b)

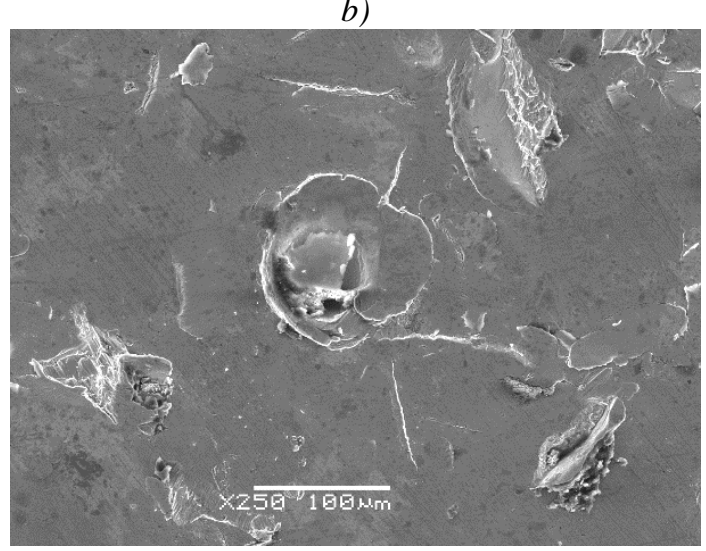

$100 \mu \mathrm{m}$

d) 


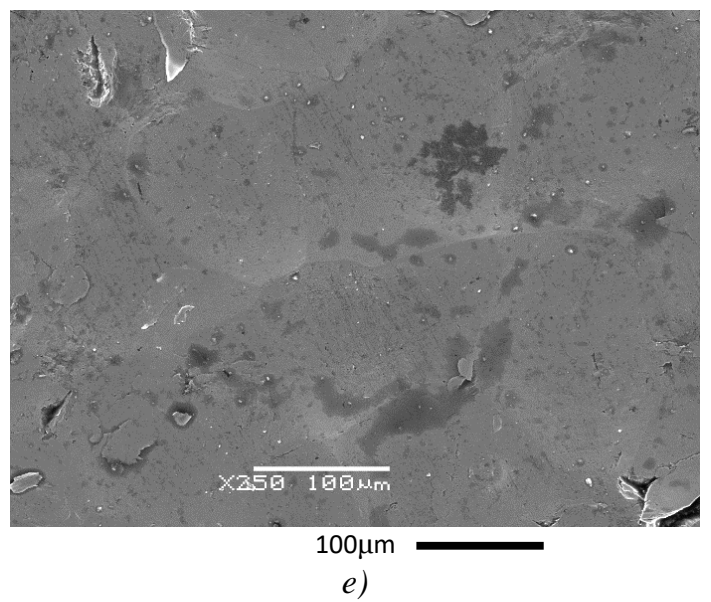

Figure 3. Topography of samples after different surface treatments.

a) SP19A 250x, b) SP19A+GB 250x, c) SP19A+SP8A-CW 250x, d) SP19A+SP8AZS 250x, e) SP8A-ZS 100\% 250x

The roughness parameters were quite similar in all series, although single low intensity shot peening treatment using zirconia shots and high intensity shot peening treatments followed by grit blasting were the ones that provided the lowest roughness. It is well known that as the applied Almen intensity decreases also does the surface roughness and, on the other hand, grit blasting using fine alumina powders remove surface material producing a roughness related to the size of the grit. Moreover, high intensity single shot peening (SP19A) yielded the largest roughness parameters and double shot peening treatments using steel and ceramic beads slightly reduces the roughness parameters. However, it was verified in a previous study [21] that roughness determination is not the best way to detect the existence of surface defects, such as folds, notches and small cracks, which may be produced in the course of shot peening due to the high energy impacts of the peening media against the treated surface. For this reason, the surface topography of the specimens was analysed after the different treatments under a scanning electron microscope, the results of which are presented in Figure 3.

It should be noted that the application of the second grit blasting treatment removes the surface layer of the samples, thus any damage generated in the first high intensity shot peening treatment is completely eliminated after grit blasting and the surface topography of these samples reproduces the geometry of the fine, angular, alumina projectiles.

In the case of double shot peening treatments, the second peening treatment partially closes the defects produced in the previous treatment, minimizing their effects, and the 
topography of these surfaces is characteristic of the smaller dimples generated in the second peening treatment.

Finally, the single low intensity shot peening treatment applied using ceramic zirconia shots gives rise to quite a flat surface topography, where the uniformity of the impressions due to the impact of the small ceramic projectiles (perfectly spherical, as shown in Figure $1)$ is worth noting.

\subsection{Residual stress profiles}

Figure 4 shows the residual stress profiles after different surface treatments. In the case of the double peening treatments, only results of $100 \%$ coverage were included, as the differences between 100 and 200\% coverage were not significant.

The profiles of all samples have approximately the same shape, with a compressive surface stress of around $-1000 \mathrm{MPa}\left(50 \% \sigma_{\mathrm{F}}\right)$, a maximum compressive stress of approximately $-1200 \mathrm{MPa}\left(60 \% \sigma_{\mathrm{F}}\right)$, at a certain depth, followed by a continuous stress decline until achieving tensile stresses at a certain depth, which defines the depth affected by the residual compression stresses, $Z_{0}$. This is the best parameter for differentiating the stress profiles obtained via the different surface treatments, the values of which are presented in Table 5. 


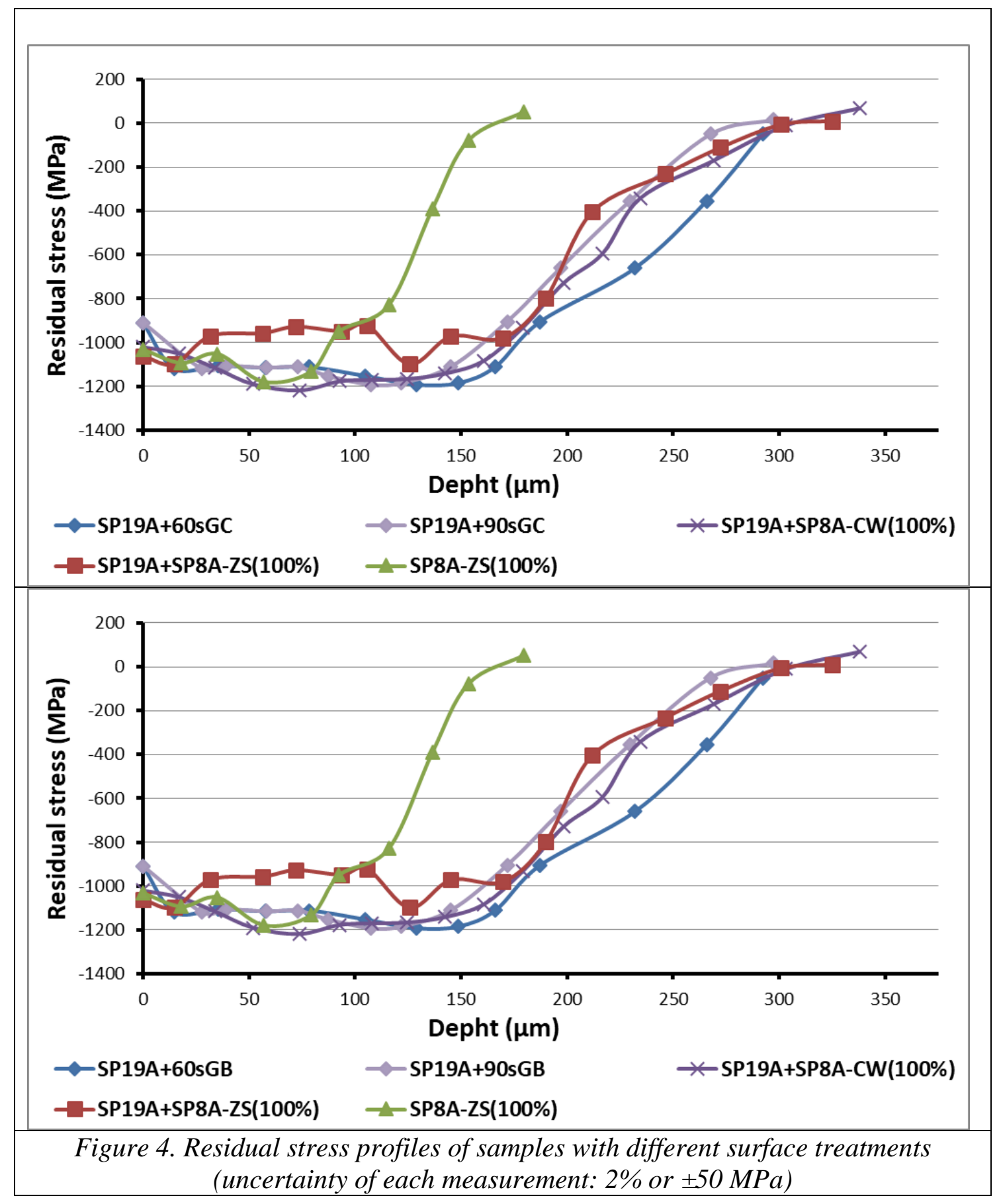

Table 5. Depth submitted to compressive residual stresses

\begin{tabular}{|c|c|}
\hline Surface treatments & $\mathrm{Z}_{0}(\mu \mathrm{m})$ \\
\hline SP19A+60sGB & 280 \\
\hline SP19A+90sGB & 255 \\
\hline SP19A+SP8A-CW(100\%) & 300 \\
\hline SP19A+SP8A-CW(200\%) & 300 \\
\hline SP19A+SP8A-ZS(100\%) & 300 \\
\hline SP19A+SP8A-ZS(200\%) & 300 \\
\hline SP8A-ZS(100\%) & 180 \\
\hline
\end{tabular}


The aforementioned affected depth reaches a value about $300 \mu \mathrm{m}$ after the double shot peening treatments (moreover, this value practically coincides with the depth affected after the first high intensity 19A peening treatment) and decreases slightly when applying the second alumina grit blasting treatments. As already stated, this is because these treatments progressively remove layers of surface material and the removed depth is directly proportional to the grit blasting time. Finally, the lowest depth affected by the presence of residual compression stresses corresponds to the single low intensity 8A ceramic shot peening treatment, because, as is well known, there exists a direct relationship between the applied Almen intensity and the induced depth protected by residual stresses.

\subsection{Fatigue lives}

Figure 5 shows the individual fatigue results and the average fatigue life obtained after the application of the different mechanical surface treatments, under an alternative stress of $55 \%$ of the ultimate tensile strength of the steel. The dispersion of the results is quite high in some cases, though this may be considered normal, as the alternative stress applied in these fatigue tests was intended to be quite near the fatigue strength (infinite life).

It is now necessary to remember that fatigue tests were carried out under rotating bending loads, where the alternative applied stress (1100 MPa) reached its maximum value on the surface of the specimen, descending linearly until it becomes zero in their central axis, located at a depth of $3 \mathrm{~mm}$ (specimens with a diameter of $6 \mathrm{~mm}$ ). Under these conditions fatigue cracks are expected to initiate on the surface of the specimen. Nevertheless, Figure 5 also shows that initiation of the fatigue cracks was internal in most of the tests (marked by a black line in the bar). In the remaining tests, fatigue cracks initiated in the sample surface due to the existence of surface defects. It is also worth noting that those tests in which fatigue cracks initiated internally always gave rise to the highest fatigue life. 


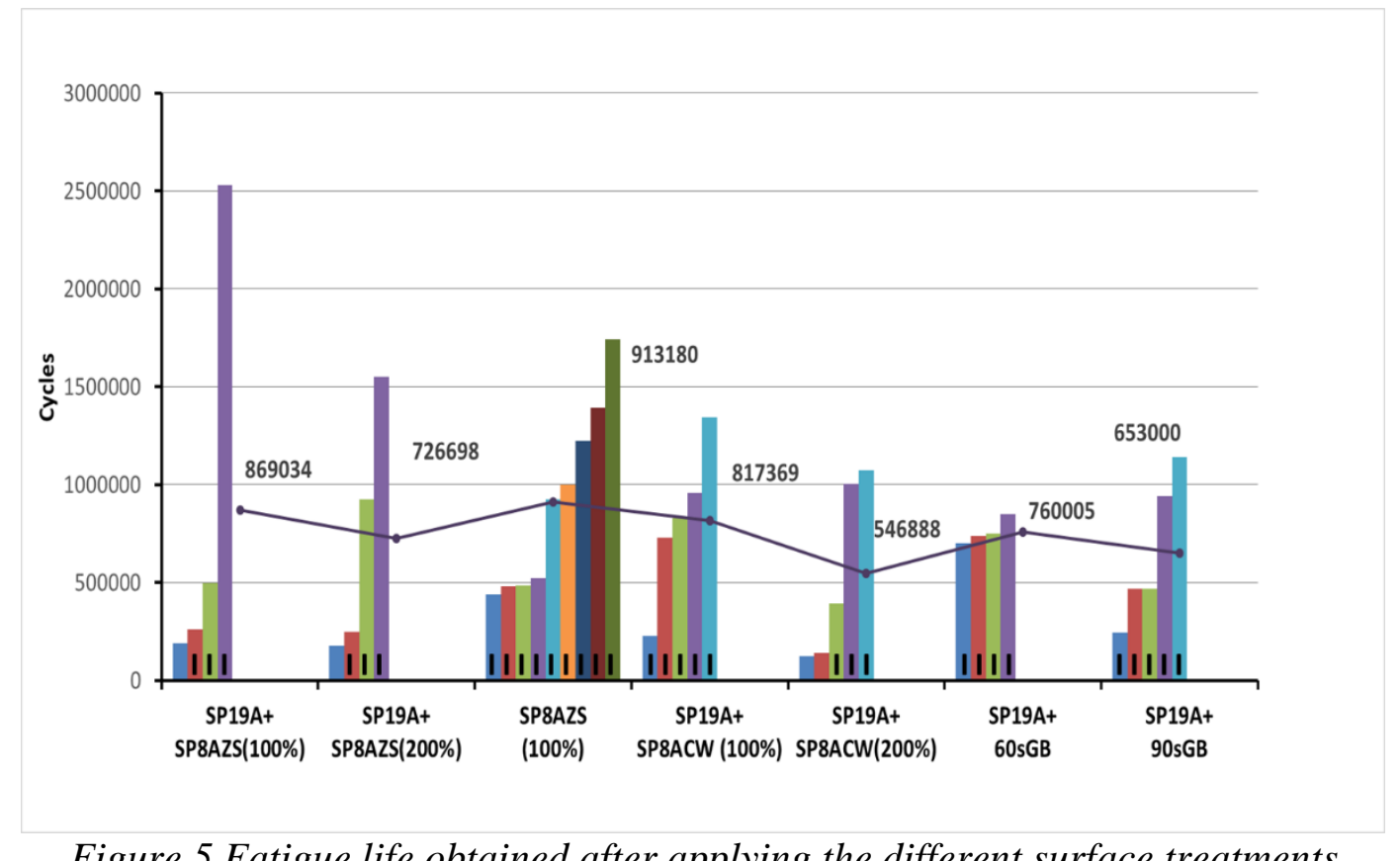

Figure 5.Fatigue life obtained after applying the different surface treatments

\section{DISCUSSION}

As already noted, most of the surface treated specimens tested in this study give rise to internal fatigue crack initiation. One example of these fracture surfaces is shown in Figure 6 , in which it is possible to observe the crack initiation and growth region due to fatigue micromechanisms, also in addition to the existence of a non-metallic inclusion responsible for the stress concentration which produced the onset of damage (inclusion location is shown by the arrows in Figure $6 \mathrm{a}$ and $\mathrm{b}$ ). These inclusions were analysed under the scanning electron microprobe and was found to be mixed oxides of aluminium, magnesium and/or calcium in all cases. All internal fatigue crack initiation failures had the same appearance. 


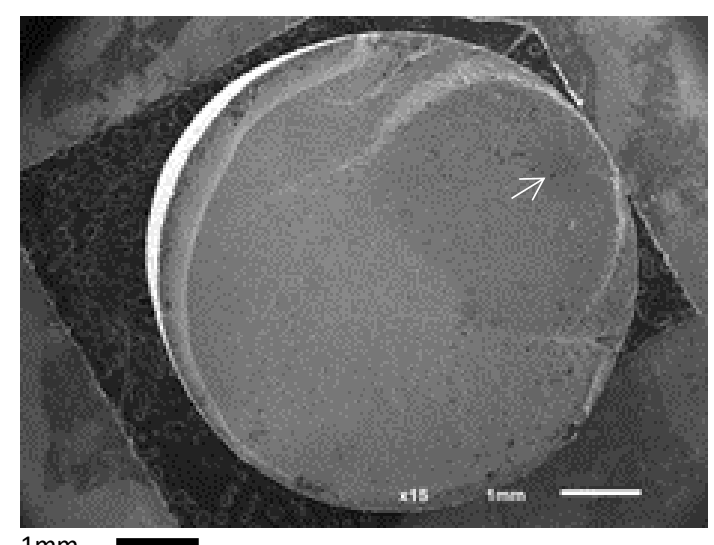

a)

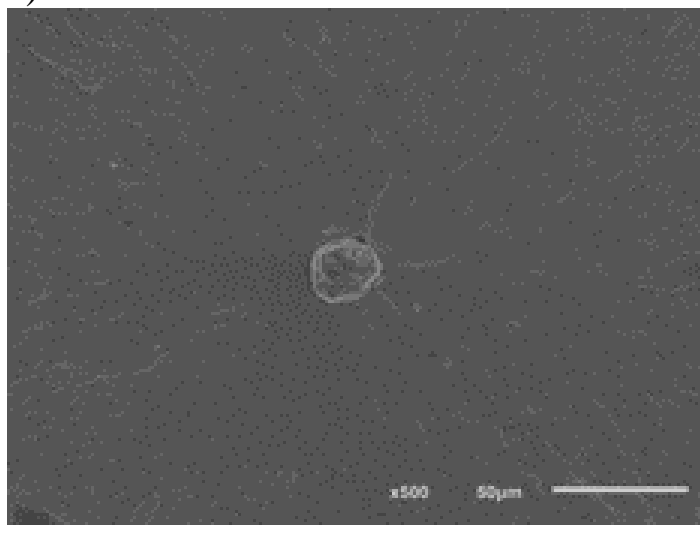

$50 \mu \mathrm{m}$

c)

Figure 6. a) Fracture surface, $15 x, b$ ) Initiation and growth region of the fatigue crack, $75 x, c)$ Region around the non-metallic inclusion, 500x and d) Non-metallic

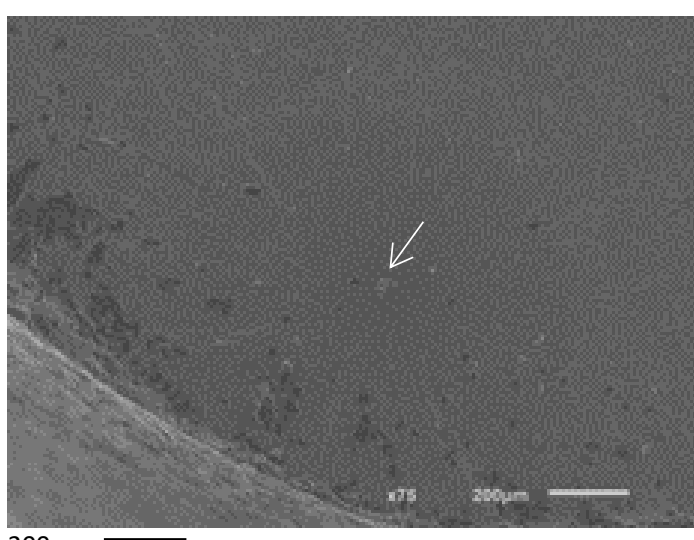

b)

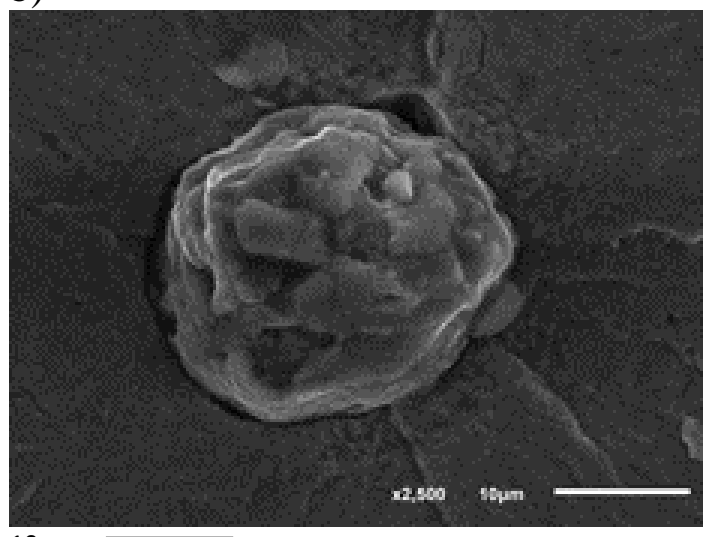

$10 \mu \mathrm{m}$

d)

\section{inclusion, 2500x}

Figure 7 shows the depth of crack initiation, $\mathrm{X}_{0}$, versus the depth protected by the compressive residual stresses, $\mathrm{Z}_{0}$, measured on the specimens with internal fatigue crack initiation. Note that the non-metallic internal inclusions where fatigue crack initiate were always located in a region where the residual compressive stress had disappeared or had been significantly attenuated, especially if we take into account the stress relaxation that always takes place during cycle loading [22,23]. 


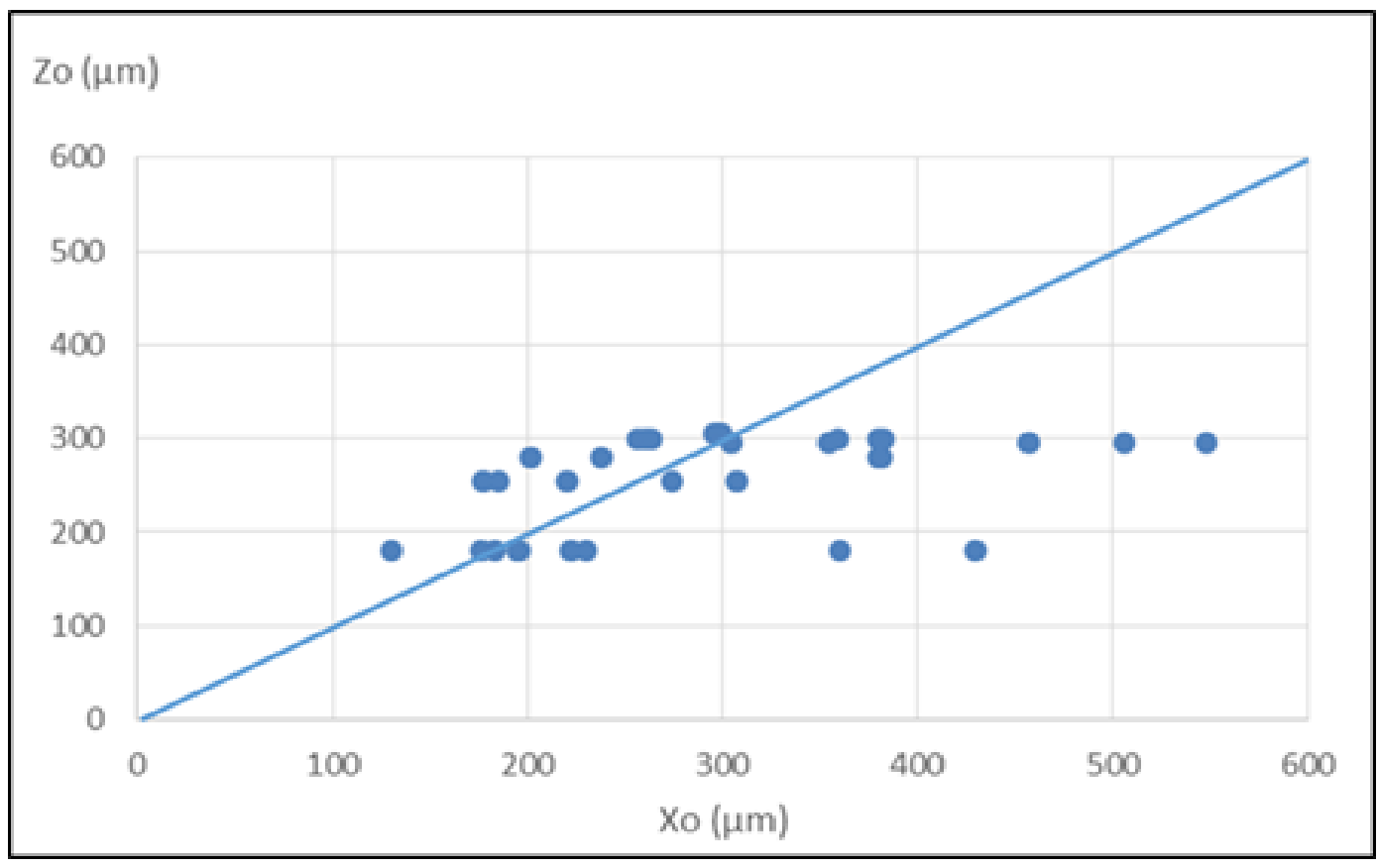

Figure 7. Fatigue crack initiation depth, Xo, versus depth protected by the compressive residual stresses, Zo

As stated previously, fatigue tests were carried out under four-point rotating bending in which the applied alternative surface stress reaches its maximum value on the surface of the cylindrical specimens, this stress linearly declining until reaching zero in the central axis, located at $3 \mathrm{~mm}$ (recall that samples had a diameter of $6 \mathrm{~mm}$ ). Internal initiation of the fatigue crack means that the applied surface treatment has generated a protective belt due to the presence of compressive residual stresses, $\sigma_{R}$. This means that the amplitude of the stress intensity factor acting on the largest defect on the surface layer of the specimen will be lower than the amplitude of the stress intensity factor that would act in a large inclusion located at a certain depth outside the area of influence of the residual compressive stress. Figure 8 shows the evolution of the applied stress $\left(\sigma_{a}\right)$, the residual stress $\left(\sigma_{R}\right)$ and the effective total stress $\left(\sigma_{t}=\sigma_{a}+\sigma_{R}\right)$ from the surface along the specimen radius. It can be seen that the local effective stress acting on an inclusion situated outside the region submitted to compressive residual stresses is larger than the effective stress in the specimen surface under bending loads. 


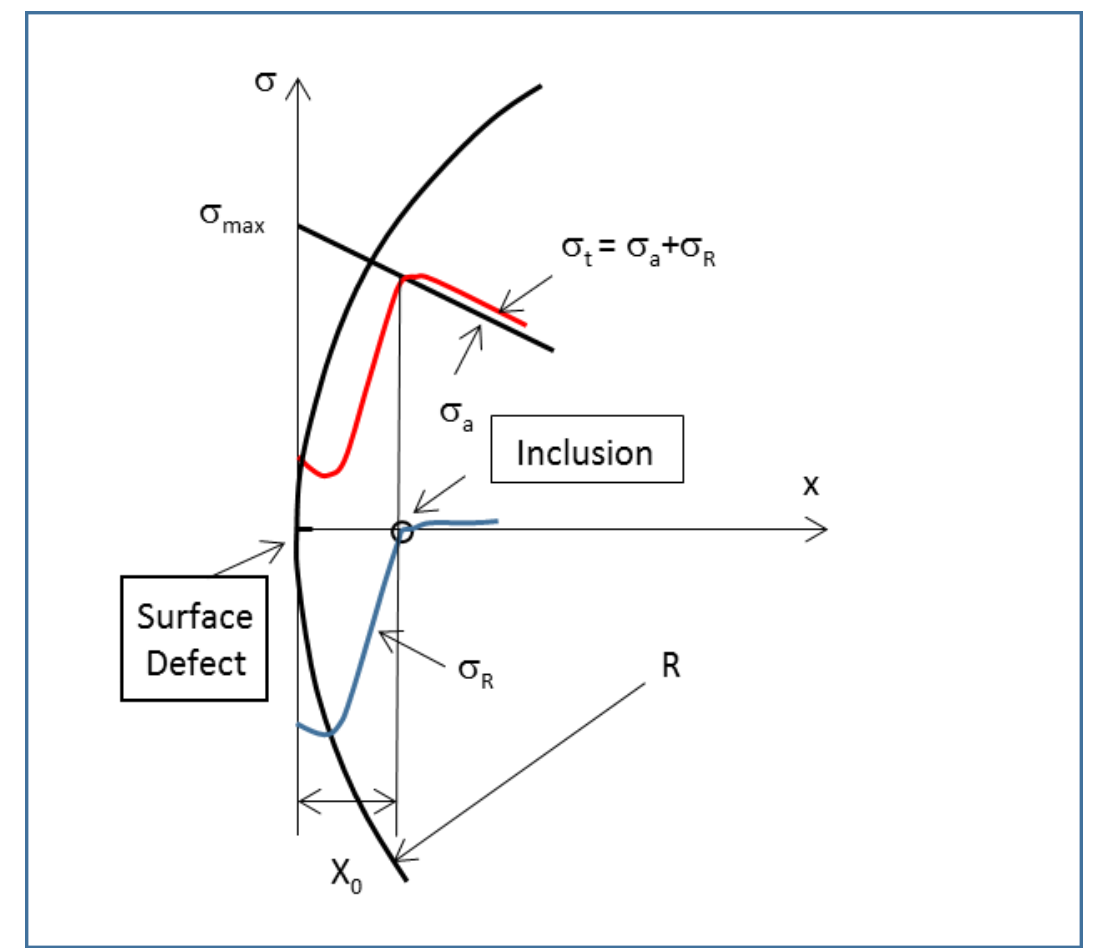

Figure 8. Stresses under bending on shot peening fatigue specimens with surface defects and internal inclusions

The amplitude of the stress intensity factor associated with the presence of internal inclusions can be calculated using the equation proposed by Murakami for ellipsoidal inclusion shapes (Equation 1) [24], where $\sigma$ is the applied tensile stress and $S_{0}$ the projected area of the 3-D inclusion onto the plane perpendicular to the tensile axis:

$$
K=0.5 \sigma \sqrt{\pi \sqrt{S_{0}}}
$$

Assuming that the inclusion giving rise to the fatigue crack initiation was located at a depth where residual stress is minimal (Figures 7 and 8) and also taking into account the linear variation of the local stress with depth for the specimen under bending stresses (Equation 2):

$\sigma_{l o c}=\sigma_{\max }\left(\frac{R-X_{0}}{R}\right)$

the amplitude of the stress intensity factor $\Delta \mathrm{K}$ for crack initiation from internal inclusions was calculated by means of Equation 3: 
$\Delta K=0.5 \Delta \sigma\left(\frac{R-X_{0}}{R}\right) \sqrt{\pi \sqrt{S_{0}}}$

where $\Delta \sigma$ is the applied stress amplitude and $\mathrm{R}$, the radius of the specimen (2200 MPa and $3 \mathrm{~mm}$, respectively, in this study).

The area of all the inclusions where internal fatigue cracks originated was measured under the scanning electron microscope. The values of the $\Delta \mathrm{K}$ factor were calculated by means of Equation (3) for all these specimens. This parameter corresponds to the value of the locally applied $\Delta \mathrm{K}$ factor that allowed the initiation and growth of fatigue cracks in these samples under rotating bending [25].

Finally, the local applied $\Delta \mathrm{K}$ value was plotted in Figure 9 versus the number of fatigue cycles until final failure of specimens, in order to determine the threshold amplitude of the stress intensity factor, $\Delta \mathrm{K}_{\text {th. }}$. A clear and progressive increase in fatigue life was observed as $\Delta \mathrm{K}$ decreases, an amplitude of $6.5 \mathrm{MPa} \sqrt{\mathrm{m}}$ finally being estimated as the fatigue threshold for infinite life for this steel. This is an intrinsic parameter, depending on the microstructure and size distribution of inclusions in the steel. Both these characteristics are responsible for the fatigue behaviour of this steel grade when fatigue crack initiation at the surface is avoided by means of appropriate surface treatments.

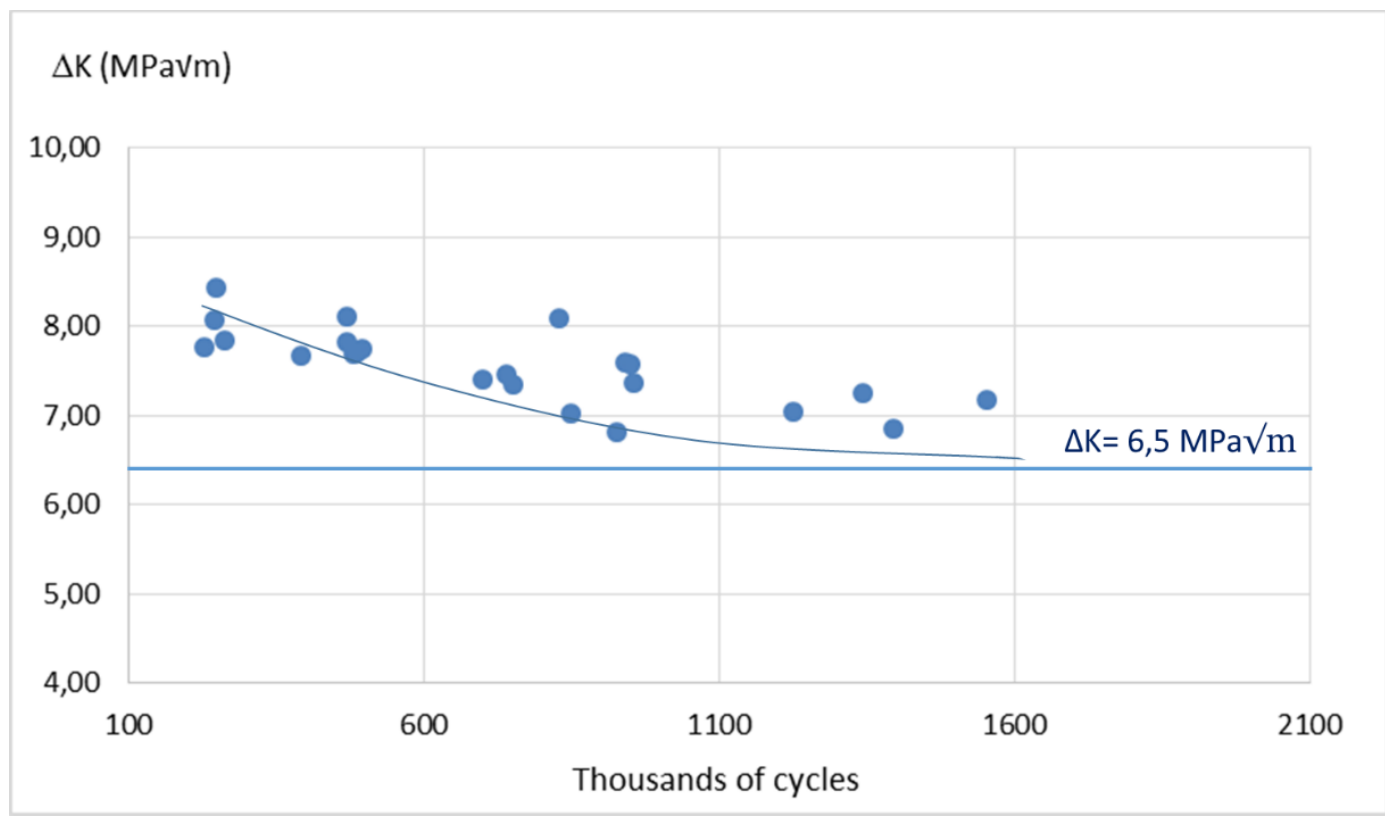

Figure 9. Applied $\Delta K$ versus number of cycles until fatigue failure 
Moreover, the projected areas of the inclusions that triggered the internal fatigue failures in our specimens were measured and their distribution was determined using extreme value statistics [26, 27]. The applied methodology can be found in the ASTM E2283 standard [28]. Each of the ' $\mathrm{n}$ ' measured inclusion areas was represented as $\mathrm{S}_{0 \mathrm{i}}$, where $1 \leq$ $\mathrm{i} \leq \mathrm{n}$. The data were arranged in increasing order such that:

$$
\mathrm{S}_{01} \leq \mathrm{S}_{02} \leq \mathrm{S}_{03} \leq \mathrm{S}_{04} \ldots \leq \mathrm{S}_{0 \mathrm{n}}
$$

The cumulative probability, $\mathrm{P}_{\mathrm{j}}(\%)$, and the reduced variants, $\mathrm{y}_{\mathrm{j}}$, for the inclusion distribution were calculated according to the following equations:

$$
\begin{aligned}
P_{i} & =i /(n+1) \\
y_{i} & =-\ln \left(-\ln P_{i}\right)=-\ln \{-\ln [i /(n+1)\}
\end{aligned}
$$

' $n$ ' being the total number of inclusions ( 23 in this case). The plot of $y_{j}$ versus the area of the inclusions, $S_{0}$, is presented in Figure 11. A linear relationship was found and a good correlation was obtained with an $\mathrm{R}^{2}$ determination coefficient of 0.986 . The projected area of the measured inclusion population in the different fatigue specimens varied between 208 and $575 \mu^{2}$, with an inclusion area of $344 \mu \mathrm{m}^{2}$ for a cumulative probability of 0.5. Moreover, using the expression of the straight line included in Figure 10, the inclusion area corresponding to cumulative probabilities of $0.01,0.1,0.9$ and 0.99 were calculated, being respectively 182, 241, 504 and $705 \mu^{2}$.

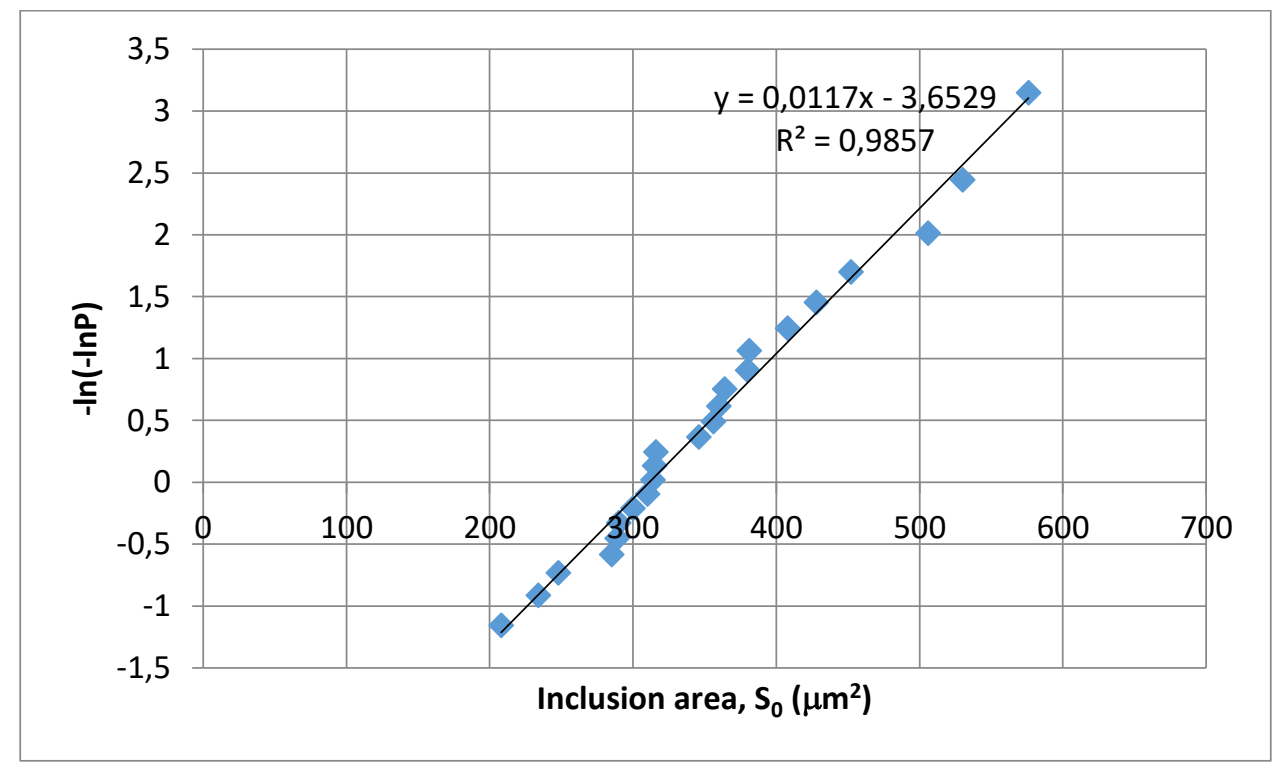


Figure 10. Reduced variate versus the cumulative distribution function of the inclusion areas measured in the fatigue failure sections of the specimens

Substituting $\Delta \mathrm{K}=\Delta \mathrm{K}_{\mathrm{th}}$ in Equation (3), the obtained $\Delta \sigma$ corresponds to the bending fatigue limit, $\Delta \sigma_{\mathrm{f}}$. The alternative stress corresponding to the bending fatigue limit of this steel, $\left(\sigma_{\mathrm{a}}=\Delta \sigma / 2\right)$, can be calculated for the different $\mathrm{Z}_{0}$ values $\left(\mathrm{Z}_{0}=\mathrm{X}_{0}\right)$ measured in the different specimens, already shown in Table 5. Using a $\Delta \mathrm{K}_{\mathrm{th}}$ value of $6.5 \mathrm{MPa} \sqrt{m}$, an average inclusion area of $344 \mu \mathrm{m}^{2}(\mathrm{P}=0.5)$ and specimen diameter of $6 \mathrm{~mm}(\mathrm{R}=3 \mathrm{~mm})$, the fatigue bending limit predicted for the four different $\mathrm{Z}_{0}$ values corresponding to the applied shot peening treatments (single peening, SP, shot peening+grit blasting, $\mathrm{SP}+\mathrm{GB}, 60 \mathrm{~s}$ and 90 s, and double peening, DP) are shown in Figure 11.

It can be seen that the calculated bending fatigue limit for this steel grade, when fatigue initiation at the surface is avoided by means of suitable surface mechanical treatments, is barely dependent on the specific applied shot peening treatment: a mere $4 \%$ decrease in the fatigue bending limit is predicted when the depth submitted to compressive residual stresses changes from $300 \mu \mathrm{m}$ (double peening treatments, DP) to $180 \mu \mathrm{m}$ (low intensity single peening, SP). Moreover, the fatigue bending stress limit obtained using the inclusion areas corresponding to cumulative probabilities of $0.01,0.1,0.9$ and 0.99 have also been represented in Figure 11. A much larger dispersion is observed in this case, showing that quite a large scattering of the fatigue results is unduly due to the statistical distribution of inclusion sizes in the microstructure of the steel. 


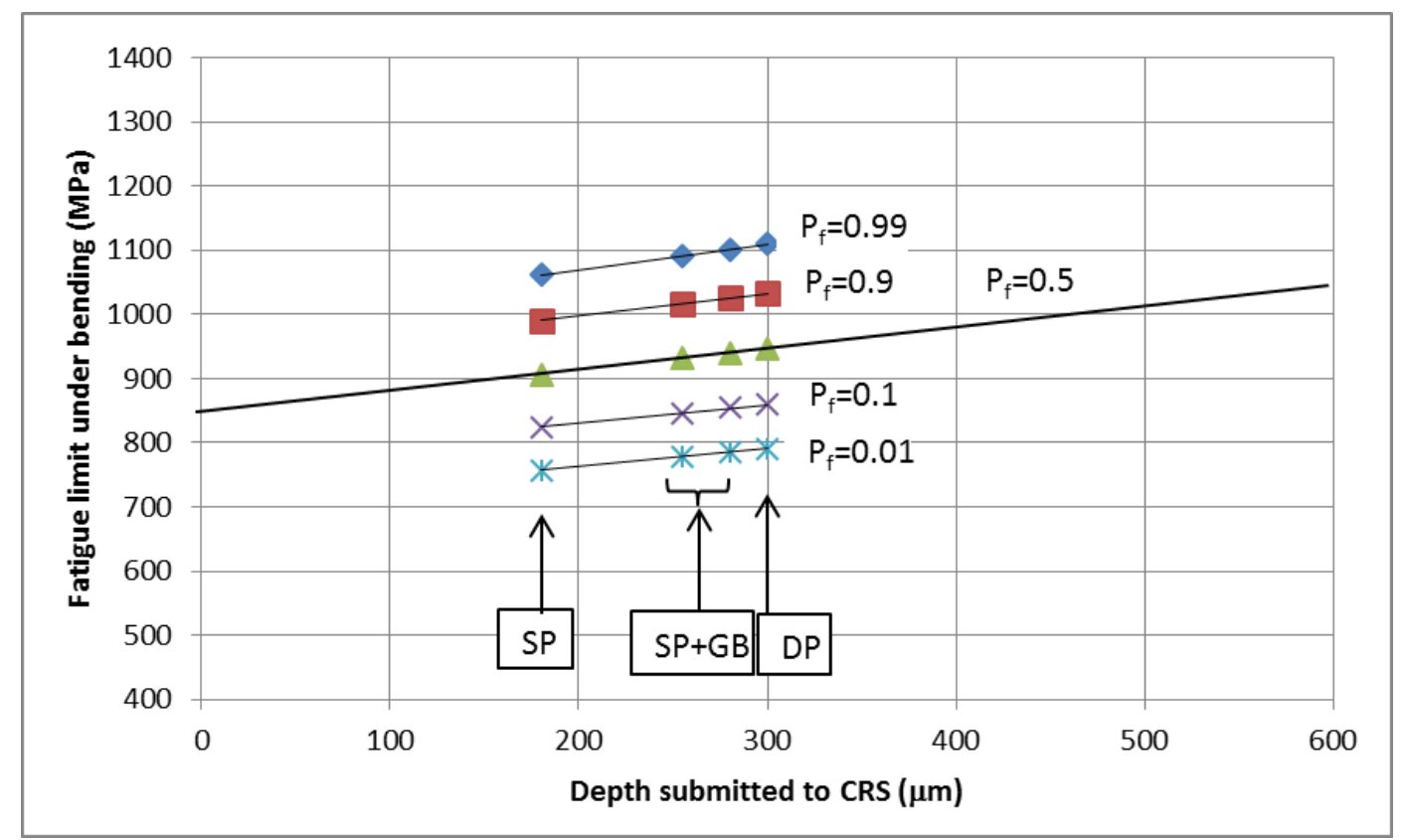

Figure 11. Fatigue bending limit calculated for the different surface treatments, single peening, SP, double peening, $D P$, and peening plus grit blasting, $S P+G B$, along with the fatigue limit corresponding to different failure probabilities associated with the inclusion distribution

It was thus demonstrated that the variation in the fatigue results shown in Figure 5, related to internal fatigue crack initiation failures once fatigue initiation at the surface is avoided by means of appropriate surface treatments, is barely dependent on the applied surface treatment (protected $\mathrm{Z}_{0}$ depth). It is however largely affected by the statistical distribution of the inclusion sizes present in the steel. Hence, the best way to improve the fatigue strength of the steel would be to use special processing techniques to obtain a cleaner product, with lower inclusion densities and smaller inclusion sizes.

\section{CONCLUSIONS}

Single surface shot peening treatments using cut wire steel and ceramic shots and additionally secondary peening and grit blasting treatments to maximize the fatigue life of a quenched and $200^{\circ} \mathrm{C}$ tempered AISI 4340 steel were studied in this work. The most important results are summarized as follows:

Topographic examination of the sample surfaces after second treatments reveals that grit blasting with fine alumina powders removes material from the surface of the samples, 
thereby completely eliminating the damage generated in the first treatment of high intensity shot peening, but leaving small defects that reproduce the angular geometry of the alumina projectiles. In the case of double peening treatments, the defects generated in the first high intensity treatment are at least partially sealed, thereby minimizing their effects, and the topography of these surfaces mainly corresponds to the smaller dimples generated in the second low intensity peening treatment. Finally, single shot peening treatment with ceramic beads, due to being a low intensity treatment and using very spherical, homogeneous beads, is the treatment that generates the smallest surface defects. On the other hand, the presence of typical shot peening defects may not be detected using any roughness parameter.

All the residual stress profiles induced by means of the applied mechanical treatments have roughly the same shape, with a compressive surface stress of around -1000 MPa and a maximum compression stress of approximately -1200 MPa located at a certain depth, followed by a continuous stress decline until entering into tensile stresses at a certain depth, which defines the depth affected by the residual compression stress, $\mathrm{Z}_{0}$. This is the best parameter for differentiating the stress profiles obtained by means of the different surface treatments, being greater in the double treatments and smaller in the single low intensity shot peening with zirconia beads.

Most of the optimized surface treated specimens submitted to rotating bending fatigue tests showed internal fatigue crack initiation associated with the existence of hard alumina inclusions. Most of these cracks were initiated from inclusions located in a region where the residual compressive stress had disappeared or had been significantly attenuated.

The threshold amplitude of the determined stress intensity factor for the studied steel, $\Delta \mathrm{K}_{\mathrm{th}}=6.5 \mathrm{MPa} \sqrt{\mathrm{m}}$, is an intrinsic parameter characteristic of the microstructure of the steel which does not depend on its surface state. Once $\Delta \mathrm{K}_{\mathrm{th}}$ is known, the fatigue bending limit of the steel for infinite life largely depends on the statistical distribution of its inclusion sizes, being barely affected by the typical compressive protected depths furnished by the shot peening treatments. 


\section{REFERENCES}

[1] MIC, Shot Peening Applications, $8^{\text {th }}$ ed., Metal Improvement Company, USA, 2001.

[2] S. Baiker (edit.), Shot peening: A dynamic application and its future, Metal Finishing News, Switzerland, 2009.

[3] J. Kritzler and W. Wübbenhorst, Inducing compressive stresses through controlled shot peening, in Hand book of residual stresses and deformation of steel, ASM International, 2003, 345-358.

[4] S. Tekeli, Enhancement of fatigue strength of SAE 9245 steel by shot peening, Matter. Lett, 57, 2002, 604-608.

[5] M.L. Aggarwald, R.A. Khan and V.P. Aggarwald, Influence of shot peening intensity on fatigue desing reliability of 65Si7 spring steel, Indian J. Eng. Mater. Sci., 12, 2005, 515-520.

[6] M.A.S. Torres and H.J.C. Voorwald, An evaluation of shot peening, residual stress and stress relaxation on the fatigue life of AISI 4340 steel, Int. J. Fatigue, 24, 2002, 877886

[7] O. Unal, Optimization of shot peening parameters by response surface methodology, Surface\&Coatings Technology, 305, 99-109, 2016.

[8] V. Llaneza and F.J. Belzunce, Optimal shot peening treatments to maximize the fatigue life of quenched and tempered steels, Journal of Materials Engineering and Performance, 24-7, 2806-2815, 2015.

[9] A.T. Vielma, V. Llaneza, F.J. Belzunce, Effect of coverage and double peening treatments on the fatigue life of a quenched and tempered structural steel, Surface \& Coatings Technology, 249, 75-83, 2014.

[10] D. Brauer, Dual peening, The shot peener, 2013, 18-20.

[11] N. Kawagoishi, T. Nagano, M. Moriyama, E. Kondo, Improvement of fatigue strength of maraging steel by shot peening, Materials and Manufacturing 
[12] SAE J442, Test strip, holder and gage for shot peening, SAE International, 2013

[13] SAE J443, Procedures for using standard shot peening Almen test strip, SAE International, 2003

[14] I.C. Noyan, J.B. Cohen, Residual Stress- Measurement by Diffraction and Interpretation, Springer-Verlag, New York, 1987 Processes, 24, 2009, 1431-1435.

[15] P.S. Prevey, X-ray diffraction residual stress techniques, in Volume 10, Materials Characterization, Metals Handbook, ASM International, 1986.

[16] D.L. Sikarskie, On a series from of correction to stresses in removed layers in X-ray diffraction, AIME Transactions, 239, 577-508, 1967.

[17] M.G. Moore y W.P. Evans, Mathematical correction for stress in removed layers in X-Ray diffraction residual stress analysis, SAE Transactions, Vol.66, 1958.

[18] NPL, Determination of residual stresses by X-ray diffraction, Document No. 52, National Physical Laboratory, UK, 2005.

[19] Fernández-Pariente I., Guagliano M., Contact fatigue damage analysis of shot peened gears by means of X-ray measurements, Engineering Failure Analysis, 16, 964971, 2009.

[20] Fernández-Pariente I., Bagherifard S., Guagliano M., Ghelichi R., Fatigue behavior of nitrided and shot peened steel with artificial small surface defects, Engineering Fracture Mechanics, 103, 2-9, 2013.

[21] E. Segurado y F.J. Belzunce, The use of double surface treatments to optimize the fatigue life of components made on structural steels, Procedia engineering, 160, 2016, $239-245$.

[22] K. Dalaei, B. Karlsson, L.E. Svensson, Stability of shot peening induced residual stresses and their influence on fatigue lifetime, Materials Science and engineering A528, 2011, 1008-1015. 
[23] J.C. Kim, S.K. Cheong, H. Noguchi, Residual stress relaxation and low- and highcycle fatigue behavior of shot-peened medium-carbon steel, International Journal of Fatigue, 56, 2013, 114-122.

[24] Y. Murakami y M. Endo, Quantitative evaluation of fatigue strength of metals containing various small defects of cracks, Engineering Fracture Mechanics, 17, 1-15, 1983.

[25] Y. Murakami, T. Kanezaki, P.Sofronis, Hydrogen embrittlement of high strength steels: Determination of the threshold stress intensity for small cracks nucleating at nonmetallic inclusions, Engineering Fracture Mechanics, 97, 227-243, 2013.

[26] S. Bereta, Y. Murakami, Largest-extreme-value distribution analysis of multiple inclusion types in determining steel cleanliness, Metallurgical and Materials Transactions, 32B, 2001, 517-523.

[27] A. Roiko, Y. Murakami, A design approach for components in ultralong fatigue life with step loading, International Journal of Fatigue, 41, 2012, 140-149.

[28] ASTM E2283, Standard practice for extreme value analysis of non-metallic inclusions in steel and other microstructure features, Annual book of ASTM standards, Vol. 03.01, 2014. 